\title{
Malnutrition and Childhood Illness among 1-5-year-old Children in an Urban Slum in Faridabad: A Cross-Sectional Study
}

\author{
Pooja Goyal ${ }^{1}$, Shveta Lukhmana ${ }^{1, *}$, Shivam Dixit ${ }^{1}$, Abhishek Singh ${ }^{2}$ \\ ${ }^{1}$ Department of Community Medicine, ESIC Medical College \& Hospital, NH-3, NIT, Faridabad, Haryana, India \\ ${ }^{2}$ Department of Community Medicine, Shahid Hasan Khan Mewati College, Nalhar, Mewat, Haryana, India
}

\section{ARTICLE INFO}

\section{Article History}

Received 24 March 2017

Accepted 22 November 2017

Keywords

Community-based

malnutrition

respiratory illness

children aged $<5$ years

urban slum

\begin{abstract}
A community-based, cross-sectional study was conducted among 202 children aged 1-5 years residing in an urban slum to study the extent of malnutrition and its association with common childhood illness(es). The participants were selected using convenient sampling (nonprobability), and the appropriate respondents were interviewed using a structured, semi-openended, pretested, interviewer-administered questionnaire. The prevalence of undernutrition (weight for age), stunting (height for age), and wasting (weight for height) were calculated at the cutoff level of $\leq 2$ standard deviation $(Z$-score $<-2)$ of the National Centre for Health Statistics (NCHS) reference median values. Data were analyzed using appropriate tests of significance. The mean age of participants was $33.9 \pm 13.9$ months. The proportion of undernutrition, stunting, and wasting among was found to be $29.2 \%, 66.8 \%$, and $12.9 \%$, respectively. Respiratory illness $(56.9 \%)$ was reportedly the most common morbidity among participants. A higher proportion of children who reportedly suffered from viral fever in past 3 months were wasted, and this association was found to be statistically significant $(p=0.003)$. The alarming rate of malnutrition reiterates the synergistic relationship between common infections and malnutrition. It is, therefore, imperative to emphasize and strengthen the role of nutritional interventions as outlined by the World Health Organization (WHO) Integrated Management of Childhood Illness as part of case management for infectious diseases among children aged $<5$ years.
\end{abstract}

(C) 2019 Atlantis Press International B.V.

This is an open access article distributed under the CC BY-NC 4.0 license (http://creativecommons.org/licenses/by-nc/4.0/)

\section{INTRODUCTION}

Half of all deaths among children aged $<5$ years are attributable to malnutrition, which translates into an unnecessary loss of about 3 million young lives per year [1]. The United Nations estimates the prevalence of underweight $[\leq-2$ standard deviation (SD) for weight for age] and wasting ( $\leq-2 \mathrm{SD}$ for weight for height) for south-central Asia to be $30 \%$ and $15 \%$, respectively [2]. According to the National Family Health Survey 4 (2015-16), the proportion of underweight ( $\leq-2$ SD for weight for age), stunting ( $\leq-2$ SD for height for age), and wasting ( $\leq-2$ SD for weight for height) among children aged $<5$ years residing in urban areas in India stands at $29.1 \%, 31 \%$, and $20 \%$, respectively [3], which is definitely lower than that of rural areas; nonetheless, this is alarming and therefore significant. The marginalized cohort of children aged $<5$ years residing in listed and unlisted urban slums are at a greater risk of malnutrition and associated complications, owing to the many vulnerabilities that their biophysical, demographic, economic, and sociocultural environment offer. These vulnerabilities translate into skewed and inequitable accessibility to basic amenities (including safe water and basic sanitation), health facilities, food insecurity, poor purchasing power parity, lack of know-how about the importance of nutrition, and its role in prevention and control of infectious diseases, to name a few. Malnutrition, as

"Corresponding author. Email: shvetalukhmana@gmail.com we understand, leads to immunological alterations [4], thereby increasing susceptibility to common infections. This, coupled with a delayed recovery, results in further deterioration of nutritional status and sets into motion a self-perpetuating cycle of malnutrition and infections, wherein each subsequent illness episode puts the child at greater risk of dying. Undernutrition (including all anthropometric measures) has been shown to be a key determinant for deaths due to diarrhea, pneumonia, and measles but do not provide an attributable fraction [5]. However, a recent systematic review has pointed out that the World Health Organization (WHO) Integrated Management of Childhood Illness strategy, which underscores the importance and reinforces the role of nutritional interventions as part of case management for infectious diseases among children aged $<5$ years [6,7], has little or no effect on stunting (low-certainty evidence) and probably little or no effect on wasting (moderate-certainty evidence) [8]. Against this background, this study was conceived to study the extent of malnutrition and its association with common illness(es) (if any) among children aged $1-5$ years residing in an urban slum of Faridabad city, Haryana, India.

\section{MATERIALS AND METHODS}

A community-based, cross-sectional study was conducted in December 2016 among 202 children aged 1-5 years residing in an 
urban slum, which is also the field practice area of the urban health and training center, Employees' State Insurance Corporation (ESIC) Medical College \& Hospital, Faridabad, Haryana, India. The total population of the selected slum was approximately 3500 . Anganwadi workers were contacted to understand the topography of the selected area, and all children between 1 and 5 years of age were included in the study using convenient (nonprobability) sampling. The interviewer made home visits and all the children aged $1-5$ years residing in the area, for whom a suitable respondent (parent, paternal or maternal aunt or grandmother) was present in the family at the time of visit, were selected. All those children whose houses were found locked despite three visits, wherein one visit was made especially on a holiday, and those for whom a reliable informant was not available at the time of visit were excluded from the study. A structured, semiopen-ended, interviewer-administered questionnaire was used. In addition, anthropometric measurements including weight (in $\mathrm{kg}$ ), length/height (in $\mathrm{cm}$ ), and mid-upper arm circumference were taken using a bathroom scale and a nonstretchable, nonelastic measuring tape, respectively. Ethical clearance was obtained from the Institutional Review Board of ESIC Medical College \& Hospital. The nature and objectives of the study were explained, and confidentiality and anonymity were assured to the respondents. Written informed consent was taken prior to the interview. A thumb impression was taken from all those respondents who could not read or write. The prevalence of undernutrition ( $\leq-2$ SD for weight for age), stunting ( $\leq-2$ SD for height for age), and wasting ( $\leq-2$ SD for weight for height) was calculated at the cutoff level of $\leq 2 \mathrm{SD}(Z$-score $<-2)$, and the prevalence of severe underweight $(\leq-3$ SD for weight for age), stunting ( $\leq-3 \mathrm{SD}$ for height for age), and wasting ( $\leq-3 \mathrm{SD}$ for weight for height) was calculated at the cutoff level of $\leq 3 \mathrm{SD}$ ( $Z$-score $\leq-3)$ of the NCHS reference median values. Data were entered into Microsoft Excel software (Microsoft, Redmond, WA, USA) and analyzed using the program. The Chi-square test was used to determine the association between childhood morbidity and malnutrition. A $p$-value of $<0.05$ was considered statistically significant.

\section{RESULTS}

In this study, the mean age of children was $33.9 \pm 13.9$ months (median age $=35.5$ months). Males $(56.4 \%$ ) outnumbered females, and $42.6 \%$ of mothers were illiterate. The majority $(74.3 \%)$ of the participants belonged to upper lower socioeconomic strata [9] (Table 1). Using the WHO Z-score for assessment of nutritional status, $29.2 \%$ of the children were found to be underweight $(\leq-2$ SD for weight for age), $66.8 \%$ were found to be stunted ( $\leq-2$ SD for height for age), and $12.9 \%$ were found to be wasted ( $\leq-2$ SD for weight for height) (Figure 1). Respondents were asked about the most common morbidities that the children suffered from in the past 3 months. Respiratory illness (56.9\%) was reportedly the most common morbidity followed by viral fever (26.2\%), vomiting $(22.3 \%)$, diarrhea $(15.3 \%)$, worm infestation (9.9\%), ear discharge (4.5\%), and jaundice (1.5\%) (Figure 2).

Data collected from the participants revealed that children who were reportedly suffering from diarrhea, vomiting, viral fever, respiratory illness, and worm infestation were underweight $(\leq-2$ SD for weight for age) as compared to those who did not suffer from illness episodes.

A greater proportion of children who were reportedly suffering from diarrhea, vomiting, ear discharge, and worm infestation were
Table 1 Sociodemographic profile of the study population $(n=202)$

\begin{tabular}{lcc}
\hline Sociodemographic variable & $\boldsymbol{n}$ & Percentage (\%) \\
\hline Age (months) & & \\
$\quad<35$ & $101(50)$ & 50.0 \\
$\quad>35$ & $101(50)$ & 50.0 \\
Sex & $114(56.4)$ & 56.4 \\
$\quad$ Male & $88(43.6)$ & 43.6 \\
$\quad$ Female & $117(57.9)$ & \\
Mother's age (in completed years) & $85(42.1)$ & 42.9 \\
$\quad<25$ years & & \\
$\quad$ 25 years & $86(42.6)$ & 42.6 \\
Mother's educational status & $116(57.4)$ & 57.4 \\
$\quad$ Illiterate & & \\
Literate & $15(7.4)$ & 7.4 \\
Socioeconomic status (as per modified & $150(74.3)$ & 74.3 \\
$\quad$ Kuppuswamy Scale) & $31(15.3)$ & 15.3 \\
$\quad$ Lower & $5(2.5)$ & 2.5 \\
$\quad$ Upper lower & $1(0.5)$ & .5 \\
$\quad$ Lower middle & \\
$\quad$ Upper middle &
\end{tabular}

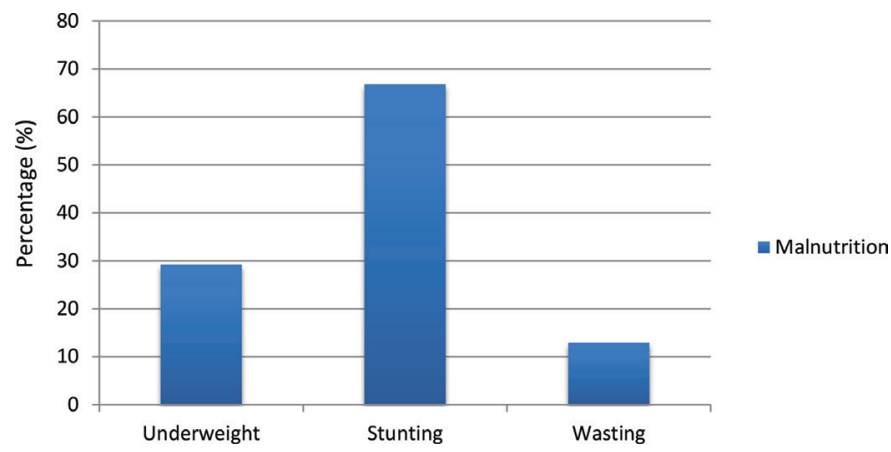

Figure 1 Prevalence of malnutrition among the children in this study $(n=202)$

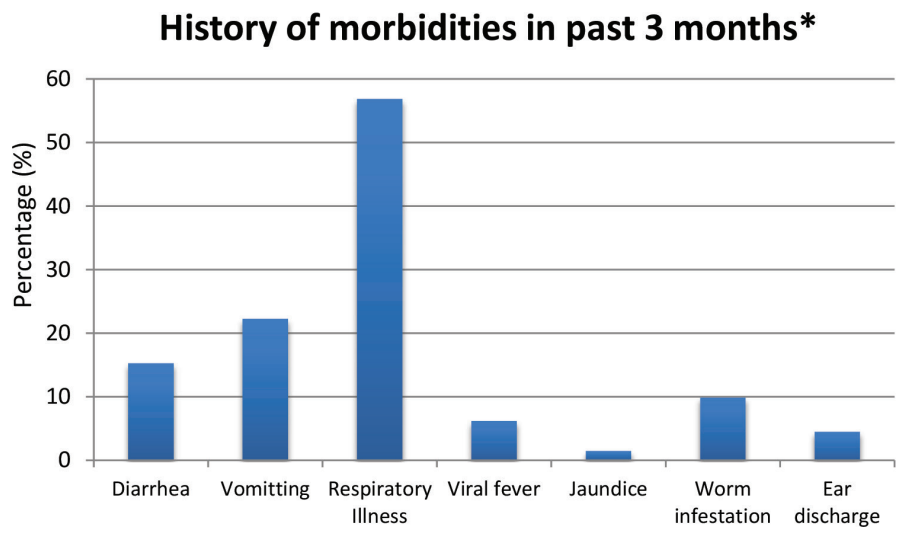

Figure 2 Morbidity profile of the children in the past 3 months based on history $(n=202)$. ${ }^{*}$ Multiple responses possible

stunted ( $\leq-2$ SD for height for age) as compared to those who did not suffer from these morbidities in the past 3 months (Table 2). A higher proportion of children who were reportedly suffering from diarrhea, vomiting, viral fever, and respiratory illness were wasted ( $\leq-2$ SD for weight for height) as compared to those who did not suffer from illness episodes (Table 3). However, these 
associations were not found to be statistically significant. On the contrary, a higher proportion of children who reportedly suffered from viral fever in the past 3 months were wasted $(\leq-2$ SD for weight for height), and this association was found to be a statistically significant association $(p=0.003)$ (Table 3$)$. A higher proportion of children who were reportedly suffering from diarrhea, vomiting, viral fever, and respiratory illness were underweight ( $\leq-2$ SD for weight for age) as compared to those who did not suffer from illness episodes (Table 4).

Table 2 Association between morbidities among children between 1 and 5 years of age and stunting

\begin{tabular}{llrrc}
\hline \multicolumn{2}{l}{ Type of illness reported } & Normal & Stunting & \multicolumn{1}{c}{$\boldsymbol{p}$} \\
\hline Diarrhea & Present & $8(25.8 \%)$ & $23(74.2 \%)$ & 0.344 \\
\multirow{2}{*}{ Vomiting } & Absent & $59(34.5 \%)$ & $112(65.5 \%)$ & \\
& Present & $12(26.7 \%)$ & $33(73.3 \%)$ & 0.293 \\
\multirow{5}{*}{ Ear discharge } & Absent & $55(35 \%)$ & $102(65 \%)$ & \\
\multirow{4}{*}{ Fever } & Present & $2(22.2 \%)$ & $7(77.8 \%)$ & 0.476 \\
& Absent & $65(33.7 \%)$ & $128(66.3 \%)$ & \\
Respiratory illness & Present & $13(24.5 \%)$ & $40(75.5 \%)$ & 0.120 \\
\multirow{2}{*}{ Worm infestation } & Absent & $54(36.2 \%)$ & $95(63.8 \%)$ & \\
& Absent & $39(33.9 \%)$ & $76(66.1 \%)$ & 0.796 \\
& Present & $28(32.2 \%)$ & $59(67.8 \%)$ & \\
& Absent & $5(25 \%)$ & $15(75 \%)$ & 0.414 \\
\hline
\end{tabular}

Table 3 Association between morbidities among children between 1 and 5 years of age and wasting

\begin{tabular}{llrrc}
\hline \multicolumn{2}{l}{ Type of illness reported } & Normal & Wasting & \multicolumn{1}{c}{$\boldsymbol{P}$} \\
\hline Diarrhea & Present & $25(80.6 \%)$ & $6(19.4 \%)$ & 0.241 \\
\multirow{2}{*}{ Vomiting } & Absent & $151(88.3 \%)$ & $20(11.7 \%)$ & \\
& Present & $37(82.2 \%)$ & $8(17.8 \%)$ & 0.265 \\
Ear discharge & Absent & $139(88.5 \%)$ & $18(11.5 \%)$ & \\
& Present & $8(88.9 \%)$ & $1(11.1 \%)$ & 1.000 \\
Fever & Absent & $168(87 \%)$ & $25(13 \%)$ & \\
\multirow{2}{*}{ Respiratory illness } & Present & $40(75.5 \%)$ & $13(24.5 \%)$ & 0.003 \\
\multirow{2}{*}{ Worm infestation } & Absent & $136(91.3 \%)$ & $13(8.7 \%)$ & \\
& Absent & $97(84.3 \%)$ & $18(15.7 \%)$ & 0.175 \\
& Present & $79(90.8 \%)$ & $8(9.2 \%)$ & \\
& Absent & $18(90 \%)$ & $2(10 \%)$ & 0.686 \\
\hline
\end{tabular}

Table 4 Association between morbidities among children between 1 and 5 years of age and underweight

\begin{tabular}{llrrr}
\hline \multicolumn{2}{l}{ Type of illness reported } & Normal & Underweight & \multicolumn{1}{c}{$\boldsymbol{p}$} \\
\hline Diarrhea & Present & $21(67.7 \%)$ & $10(32.3 \%)$ & 0.685 \\
& Absent & $122(71.3 \%)$ & $49(28.7 \%)$ & \\
Vomiting & Present & $30(66.7 \%)$ & $15(33.3 \%)$ & 0.49 \\
\multirow{3}{*}{ Ear discharge } & Absent & $113(72 \%)$ & $44(28 \%)$ & \\
& Present & $9(100 \%)$ & $0(0 \%)$ & $0.061^{*}$ \\
Fever & Absent & $134(69.4 \%)$ & $59(30.6 \%)$ & \\
\multirow{2}{*}{ Respiratory illness } & Present & $33(62.3 \%)$ & $20(37.7 \%)$ & 0.112 \\
& Absent & $110(73.8 \%)$ & $39(26.2 \%)$ & \\
Worm infestation & $80(69.6 \%)$ & $35(30.4 \%)$ & 0.659 \\
& Absent & $63(72.4 \%)$ & $24(27.6 \%)$ & \\
& Present & $14(70 \%)$ & $6(30 \%)$ & 0.935 \\
\hline
\end{tabular}

"Fischer's exact test.

\section{DISCUSSION}

Our study shows high proportions of underweight $(29.2 \%)$, stunting $(66.8 \%)$, and wasting (12.9\%) among 1 - to 5-year-old children residing in an urban slum. Relatively higher proportions have been reported by Mittal et al. [10] in a study conducted across three urban slums of Tripuri Town, Patiala, among children of $1-5$ years of age wherein $38.38 \%$ children were found to be underweight and $46.06 \%$ were fund to be stunted [10]. Meanwhile, similar findings were reported by Rose et al. [11] in a study conducted in rural Zambezia Province, Mozambique, wherein $55 \%$ children were found to be malnourished. The most common form of malnutrition was stunting (51\%), followed by underweight (13\%) and wasting (5\%). Malnutrition among children aged $<5$ years is a serious public health problem especially among the urban poor residing in (urban) slums as was seen in this study. The study population consisted of a marginalized, vulnerable, and, sadly, neglected cohort of urban poor who migrated to industrialized, urbanized, and therefore developed areas, in search of better opportunities of livelihood to have an improved quality of life, and instead had to settle for poorly paid, unskilled jobs to make ends meet. This resulted in a poor socioeconomic status, as is indicated in our study wherein $82 \%$ of the participants belonged to a lower socioeconomic status. This, coupled with higher proportion of illiteracy among mothers (42.6\%), jeopardizes the nutritional status among children and could have resulted in higher rates of malnutrition as seen in our study.

Respiratory and gastrointestinal illness was identified as the most common infection among children aged 1-5 years in our study. Poor socioeconomic status among these vulnerable urban poor coupled with acute and chronic malnutrition could have predisposed these children to succumb to infectious diseases. Similar findings were reported by Sarkar et al. [12] in the western outskirts of Vellore, wherein of the 3932 episodes of illness(es) that were recorded, upper respiratory and gastrointestinal were the most common. In addition, nearly one-third of the participants were found to have stunting and two-thirds had at least one episode of growth failure during the 2 years of follow-up. Similarly, Singh et al. [13] found that most prevalent childhood illnesses were respiratory diseases (7.5\%), gastroenterological diseases (7.5\%), and fever (viral fever, malaria, and jaundice) (5.6\%) [13]. Diarrhea has been shown to be the most important infectious disease determinant of stunting. A pooled analysis of nine community-based studies in low-income countries showed that the odds of stunting at 24 months of age increased multiplicatively with each diarrhea episode [2].

\section{CONCLUSION}

More than half of the children in this study were suffering from chronic malnutrition, as indicated by the alarming proportions of stunting. In addition, the prevalence of acute malnutrition, as evident from undernourished children, was quite high. Respiratory illness was reportedly the most common morbidity among participants. A higher proportion of children who reportedly suffered from viral fever in the past 3 months were wasted, and this association was found to be statistically significant. 


\subsection{Recommendations}

The alarming rate of undernutrition, stunting, and wasting among children aged $<5$ years residing in urban slums in this study reiterates the synergistic relationship between common infections and malnutrition. It is, therefore, imperative to outline the role and course of common childhood infections through longitudinal studies incorporating a mixed-methods approach to strengthen the role of nutritional interventions as outlined by the WHO Integrated Management of Childhood Illness as part of case management for infectious diseases among children aged $<5$ years.

\section{CONFLICTS OF INTEREST}

None.

\section{REFERENCES}

[1] UNICEF Data: Monitoring the Situation of Children and Women. UNICEF/WHO/World Bank Joint Child Malnutrition Estimates, September 2016 edition. Available from: http/data.unicef.org [Updated 28 Feb, 2017].

[2] Black RE, Victora CG, Walker SP, Bhutta ZA, Christian P, de Onis $\mathrm{M}$, et al. Maternal and child undernutrition and overweight in low-income and middle-income countries. Lancet 2013;382;427-51.

[3] International Institute of Population Sciences and ORC Macro. National Family Health Survey. International Institute of Population Sciences, Mumbai. 2014. Available from: http://rchiips. org/NFHS/pdf/NFHS4/India.pdf [Accessed on August 17 2017].
[4] Rytter MJH, Kolte L, Briend A, Friis H, Christensen VB. The immune system in children with malnutrition-a systematic review. PLoS ONE 2014;9;e105017.

[5] Black RE, Morris SS, Bryce J. Where and why are 10 million children dying every year? Lancet 2003;361;2226-34.

[6] Lambrechts T, Bryce J, Orinda V. Integrated management of childhood illness: a summary of first experiences. Bull World Health Organ 1999;77;582-94.

[7] Tulloch J. Integrated approach to child health in developing countries. Lancet 1999;354;16-20.

[8] Gera T, Shah D, Garner P, Richardson M, Sachdev HS. Integrated management of childhood illness (IMCI) strategy for children under five. Cochrane Database Syst Rev 2016;1-61.

[9] Sharma R. Online Interactive calculator for real-time update of the Kuppuswamy's socio-economic status scale. Available from: www.scaleupdate.weebly.com [Accessed on June 22 2017].

[10] Mittal A, Singh J, Ahluwalia SK. Effect of maternal factors on nutritional status of 1-5-year-old children in urban slum population. Indian J Community Med 2007;32;264-7.

[11] Rose ES, Blevins M, González-Calvo L, Ndatimana E, Green AF, Lopez $\mathrm{M}$, et al. Determinants of undernutrition among children aged 6 to 59 months in rural Zambézia Province, Mozambique: results of two population-based serial cross-sectional surveys. BMC Nutr 2015;1;41.

[12] Sarkar R, Sivarathinaswamy P, Thangaraj B, Sindhu KNC, Ajjampur SSR, Muliyil J, et al. Burden of childhood diseases and malnutrition in a semi-urban slum in southern India. BMC Public Health 2013;13;87.

[13] Singh MB, Lakshminarayana J, Fotedar R, Anand PK. Childhood illnesses and malnutrition in under five children in drought affected desert area of Western Rajasthan, India. J Commun Dis $2006 ; 38 ; 88-96$. 